\title{
Bio-ethanol production from poultry manure at Bonga Poultry Farm in Ethiopia
}

\author{
Asrat Gebremariam Woldesenbet ${ }^{1 *}$, Gizachew Shiferaw ${ }^{1}$ and Bhagwan Singh Chandravanshi ${ }^{2}$ \\ ${ }^{1}$ School of Chemical and Bio-Engineering, Addis Ababa Institute of Technology, Addis Ababa University, \\ P.O. Box 385, Addis Ababa, Ethiopia. \\ ${ }^{2}$ Department of Chemistry, Faculty of Sciences, Addis Ababa University, P.O.Box 1176, Addis Ababa, Ethiopia.
}

Accepted 13 June, 2013

\begin{abstract}
This study aimed to determine bio-ethanol potential of poultry manure. The manure was hydrolyzed by dilute $\mathrm{H}_{2} \mathrm{SO}_{4}(0.2,0.4,0.6,0.8$ and $1 \mathrm{M})$ at temperature of 100 and $130^{\circ} \mathrm{C}$ for $30 \mathrm{~min}$. Maximum glucose (115.6 g/l) was obtained from hydrolysis of $100 \mathrm{~g}$ poultry manure by $0.8 \mathrm{M} \mathrm{H}_{2} \mathrm{SO}_{4}$ at $100^{\circ} \mathrm{C}$ for $30 \mathrm{~min}$. The study shows that treatment of poultry manure releases more total reducing sugar using $0.8 \mathrm{M} \mathrm{H}_{2} \mathrm{SO}_{4}$. Refractometry analysis of the fermented hydrolysate gave maximum ethanol concentration of $5 \% \mathrm{w} / \mathrm{v}$ with $0.8 \mathrm{M} \mathrm{H}_{2} \mathrm{SO}_{4}$ and 4, 4, 3 and $2.5 \%$ of ethanol with 1, 0.6, 0.4 and $0.2 \mathrm{M} \mathrm{H}_{2} \mathrm{SO}_{4}$ hydrolysis at $130^{\circ} \mathrm{C}$ for $30 \mathrm{~min}$, respectively. Treatment with $0.8 \mathrm{M}$ acid is an effective way that results to maximum yield and treatment with $0.2 \mathrm{M}$ acid is the least effective. The optimum fermentation time is $\mathbf{2 4} \mathrm{h}$.
\end{abstract}

Key words: Bioethanol, bio-mass, fermentation, conversion, ethanol fuel.

\section{INTRODUCTION}

The high solubility of poultry manure in water provides a strong possibility for the occurrence of water pollution. The application of excessive amounts of poultry manure can result in the leaching of nutrients through the soil and into the local groundwater. Efficient manure management ensures that manure or its constituents cannot gain access to rivers, streams, lakes or water supplies (Akpan et al., 2008).

One of the greatest challenges for the growing society in this century is to meet the energy demand for transportation, heating, lighting and industrial processes, which have significant impact on the environment. These challenges demand an urgent need to carry out research to find out the viable alternative fuels (Akpan et al., 2008).

The Energy Independence and Security Act (EISA) mandate that at least 16 billion gallons (61 billion liters) per year of cellulosic fuel be in production by the year 2022. To meet this ambitious goal, many feedstocks, with appropriate conversion technologies, will be required for fuel production (Budsberg et al., 2012).

One of the promising alternative fuels to gasoline in the transport sector is bio-ethanol. Fuel ethanol is known as bio-ethanol, since it is produced from plant materials by biological processes. Bioethanol is mainly produced by fermentation of sugar containing crops like corn, maize, wheat, sugar cane, sugar beet, potatoes, sorghum and cassava (Akpan et al., 2008).

There are lots of other alternative fuels such as methanol, methane, natural gas, propane, hydrogen, etc. Nevertheless, the remarkable characteristics of ethanol distinguish it as the best alternative fuel for automobile. It has high latent heat of vaporization, high octane number and rating, and emission of toxic compounds on its combustion is low (Akpan et al., 2008).

Approximately $80 \%$ of the ethanol produced in the world is still obtained from fermentation (Gunasekaran, 2007); the remainder comes largely by synthesis from the petroleum product ethylene (Tanaka, 2006). All the 
ethanol used for fuel and green house gas and they are responsible for global warming and climate change. Nowadays, research on alcoholic drinks, and most industrial ethanol, is made by this process (Licht, 2001). In 2002 , world ethanol production was projected at 34 million $\mathrm{m}^{3}$ (Licht, 2007).

Fuel ethanol is the largest market by far, accounting for $60 \%$ of total ethanol production worldwide (Licht, 2001). This share is likely to increase over the coming years as many countries set up fuel ethanol programmes. Industrial ethanol accounts for $20 \%$ of the market and beverages for about 15\%; both these markets are growing comparatively slowly.

According to Licht (2007), the total world production of ethanol was about 40,700 million litres(L), of which $73 \%$ was used as vehicles fuel, $17 \%$ for production of beverages and $10 \%$ for other industry needs (Anuj et al., 2007). Brazil and USA are by far the largest producers of fuel alcohol. Ethanol produced from biomass is considered as one of the modern forms of biomass energy that has the potential to be a sustainable transportation fuel for gasoline engines.

Ethanol is a clear, colorless, flammable, oxygenated hydrocarbon with the chemical formula $\mathrm{C}_{2} \mathrm{H}_{5} \mathrm{OH}$. Ethanol can be used as a transport fuel in at least four forms: anhydrous ethanol $(100 \%$ ethanol), hydrous ethanol (95\% ethanol and $5 \%$ water), anhydrous ethanol-gasoline blends (10 to $20 \%$ ethanol in gasoline) and as raw material for ethyl $t$-butyl ether (ETBE).

Bio-ethanol has a number of advantages over conventional fuels. Some of these are: it comes from a renewable resource, that is, crops and not from a finite resource, and the crops it derives from can grow well (like cereals, sugar beet and maize). The road transport network accounts for $22 \%$ of all greenhouse gas emissions and through the use of bio-ethanol, some of these emissions will be reduced as the fuel crops absorb the $\mathrm{CO}_{2}$ they emit through growing.

Blending bio-ethanol with petrol will reduce heavy reliance on oil producing nations. Bio-ethanol is biodegradable and far less toxic than fossil fuels. Ethanol has much higher latent heat of vaporization $(855 \mathrm{MJ} / \mathrm{kg})$ than petrol $(293 \mathrm{~kJ} / \mathrm{kg})$. Ethanol has a higher octane number (99) than petrol (80 to 100) as a result pre-ignition does not occur when ethanol is used: ethanol burn more completely, so that hydrocarbon emission is drastically lower as compared to petrol. Ethanol is much less likely to catch fire and explodes in case of fuel leakage. Using bio-ethanol in older engines can help to reduce the amount of carbon monoxide produced by the vehicle thus improving air quality (Attygalle, 2008). The production and use of biofuels has the potential to reduce greenhouse gas emissions, particularly with the development of bioethanol from agricultural wastes or lignocellulosic crops (Scott et al., 2013).

The use of fossil fuel in cars releases carbon dioxide, carbon monoxide, sulfur dioxide, oxides of nitrogen and heavy metals. These gases are the main constituents of non-food crops and cellulosic materials is getting great attention worldwide because they are cheap, easily available, and profitable as compared to food crops and also reduces inflation of the cost of food crops used for bio-ethanol production.

Animal manures have been used effectively as fertilizers for centuries. Poultry manure has long been recognized as perhaps the most desirable of these natural fertilizers because of its high nitrogen content. In addition, manures supply other essential plant nutrients and serve as a soil amendment by adding organic matter. Organic matter persistence will vary with temperature, drainage, rainfall and other environmental factors. Organic matter in soil improves moisture and nutrient retention. The utilization of manure is an integral part of sustainable agriculture.

Livestock manures contain lignocelluloses, polysaccharides, proteins and other organic materials. The conversion of these waste materials to value-added products has been recognized as an attractive alternative waste management solution (Industry Canada, Bio-Products Canada, 2004). However, as a feedstock, this organic (lignocellulosic) waste has a complex physical and chemical composition and, to date, the limited efforts to convert waste biomass to higher-value chemicals and energy on a commercial scale have been unsuccessful (Attygalle, 2008).

Preliminary research using organic waste materials as lignocellulosic feed stocks for the production of bioethanol and other value-added products has shown great promise and is capturing the interest of the bio-products industry. However, further detailed research is critical to investigate its ultimate application beyond the laboratory scale (Demirbas, 2005).

The Food and Agriculture Organization of the United Nations estimated that in 2002 there were nearly sixteen billion chickens in the world; counting a total population of $15,853,900,000$. The figures from the Global Livestock Production and Health Atlas for 2004 were as follows: China $(8,860,000,000)$, Mexico $(540,000,000)$, United States $(1,970,000,000)$, India $(425,000,000)$, Indonesia $(1,200,000,000), \quad J a p a n \quad(286,000,000), \quad$ Brazil $(1,100,000,000)$, Iran $(280,000,000)$, Russia $(340,000,000)$ and Turkey $(250,000,000)$,

Ethiopia is believed to have the largest livestock population in Africa. This livestock sector has been contributing considerable portion to the economy of the country, and still promising to rally round the economic development of the country. Livestock provides farmyard manure that is commonly applied to improve soil fertility and also used as a source of energy. Rural poultry production in Ethiopia represents a significant part of the national economy in general and the rural economy in particular, and contributes 98.5 and $99.2 \%$ of the national egg and poultry meat production, respectively (Canettieri et al., 2007), with an annual output of 72,300 metric tones of meat and 78,000 metric tones of eggs (Choge et al., 2007). 
Total poultry population in Ethiopia is estimated to be about 38.13 million. Cocks and cockerels are also estimated separately, and are 4.01 and 1.78 million, respectively. The others are non-laying hens that make up about $3.99 \%$ (1.52 million) of the total poultry population in the country. With regard to breed, $96.4,3.06$ and $0.53 \%$ of the total poultry were reported to be indigenous, hybrid and exotic, respectively.

Small and large scale chicken farms are rapidly growing in Ethiopia. Some of the poultry farms are found in Addis Ababa, Debre Zeit, Awassa, Wolaita Sodo, Benshagul Gumuz Regional State and Bonga (the study area). Furthermore, private farms (Alema and Genesis Farms from Debre Zeit, four small-scale poultry farms in Addis Ababa), two Poultry Multiplication and Distribution Centers in Awassa and Wolaita Sodo, and backyard farms in Wolaita Sodo and Benshangul Gumuz Regional State.

This research was conducted to investigate bioethanol production potential of poultry manure and provide environment friendly alternatives to make use of poultry manure. Thus, the objectives of the present study were: (i) to determine the quantity of reducing sugars produced from the $\mathrm{H}_{2} \mathrm{SO}_{4}$ hydrolysis of poultry manure at different acid concentrations and at different temperatures by liquid chromatography and optical rotation and (ii) to determine the quantity of ethanol produced from the fermentation of reducing sugars at different fermentation times by refractometry.

\section{MATERIALS AND METHODS}

\section{Materials and chemicals}

Fermentation bottles (Erlenmeyer flask, 250 to $500 \mathrm{ml}$ ), yeast (Saccharomyces cerevisiae), sulfuric acid (98\%, sd fine-chem. limited, Mumbai), poultry manure, high performance liquid chromatography (HPLC) (2053E00X, ECOM Ltd, Czech Republic), Polarimeter (AUTOPOL IV, Rudolph, USA), vacuum filter, sealed plastic bucket, centrifuge, oven (VO200, memmert, Germany) and grinder were used throughout the experiment.

\section{Methods}

Alcohol was produced by preparing sugar-containing raw material for fermentation by yeast. The experimental work was designed to determine the ethanol content of poultry manure. Ethanol was produced from the manure by the hydrolysis and sugar fermentation processes. In order to produce sugars from the manure, it was pre-treated with acid and the hemicellulose portions was broken down (hydrolyzed) by dilute acids into different sugars that was then fermented into ethanol.

\section{Feedstock material collection and preparation}

Poultry manure with no bedding material was collected from Bonga Poultry Farm (Ethiopia). The solid manure was transported in a sealed plastic bucket. Priortotreatment, manuresamples were thawed in a refrigerator at $4^{\circ} \mathrm{C}$ for $24 \mathrm{~h}$ and then mixed. The raw poultry manure feedstock was washed with distilled water and the sand was removed through sedimentation, the remaining solid fraction was employed in the experimental investigation and the liquid portion which may have negative effect on the environment is kept for treatment before disposal. It needs characterization of the liquid before discharging to the environment. The washed poultry manure was neutralized to a $\mathrm{pH}$ of 7.0 with $0.5 \mathrm{M} \mathrm{H}_{2} \mathrm{SO}_{4}$. The neutralized manure solution was then centrifuged for $10 \mathrm{~min}$ at 4,700 rpm. The solid fraction was refrigerated at $4^{\circ} \mathrm{C}$ in plastic bottles prior to acid hydrolysis.

\section{Dilute acid hydrolysis}

The poultry manure $(100 \mathrm{~g})$ was hydrolyzed (pretreated) with 250 $\mathrm{ml}$ of different concentrations of sulfuric acid $(0.2,0.4,0.6,0.8 \mathrm{M}$ and $1 \mathrm{M}$ ) in $500 \mathrm{ml}$ Erlenmeyer flask and separately heated at 100 and $130^{\circ} \mathrm{C}$ for $30 \mathrm{~min}$ using oil thermostat. After hydrolysis, the liquid fraction was cooled, filtered and determined for glucose concentration using HPLC and polarimeter. The acid hydrolysates were adjusted to $\mathrm{pH} \mathrm{5-6}$ by adding concentrated sulfuric acid and 1 $M$ sodium hydroxide, and the solutions were filtered and prepared for fermentation (Dawson and Boopaty, 2008).

\section{Fermentation process}

The hydrolysis process breaks down the cellulose part of the manure into sugar solutions and yeast was added to the solution, which was then heated. Bach fermentations of hydrolysates were carried out in flask incubated with $5 \mathrm{~g} / \mathrm{l}$ yeast ( $\mathrm{S}$. cerevisiae) at $30^{\circ} \mathrm{C}$, as described in the literature (Thuesombat et al., 2007). The hydrolysates of $0.2,0.4,0.6,0.8$ and $1 \mathrm{M}$ sulfuric acid treated hydrolysates are fermented with $5 \mathrm{~g} / \mathrm{l}$ yeast. The overall process is shown in Figure 1.

\section{RESULTS AND DISCUSSION}

\section{Reducing sugar concentration versus acid concentration}

The experimental results showed that the sample (poultry manure) has good reducing sugar potential. The results also showed that the amount of total reducing sugar in the sample increases with increase in acid concentration used for hydrolysis and temperature of hydrolysis. The results are given in Table 1.

Table 1 shows that all expected reducing sugars are detected by hydrolysis of $0.8 \mathrm{M} \mathrm{H}_{2} \mathrm{SO}_{4}$. It can also be seen that some of the reducing sugars (fructose, glucose and sucrose) are detected from breaking down of cellulosic material in the sample on hydrolysis using 1 and 0.6 $\mathrm{M} \mathrm{H}_{2} \mathrm{SO}_{4}$. While only one of the expected reducing sugars (fructose) is detected on hydrolysis using $0.4 \mathrm{M}$ $\mathrm{H}_{2} \mathrm{SO}_{4}$, which indicates the concentration of the acid used for hydrolysis of the sample is not able to break cellulosic materials in the sample completely. In the similar manner, only one of the components of expected reducing sugars (fructose) is detected with much reduced peak area on hydrolysis using $0.2 \mathrm{M} \mathrm{H}_{2} \mathrm{SO}_{4}$. 


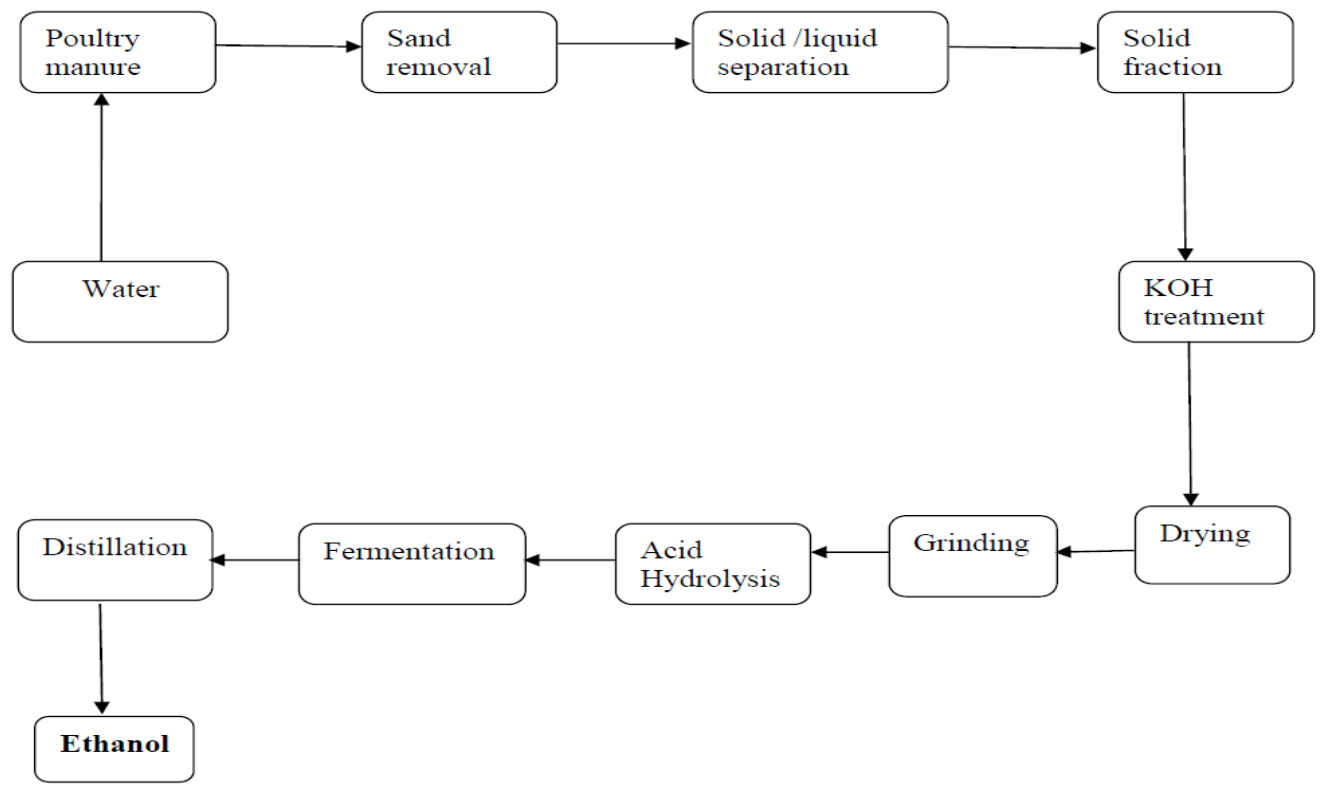

Figure 1. General process flow diagram.

Table 1. Chromatographic results of the samples hydrolyzed by $1.0,0.8,0.6,0.4$ and $0.2 \mathrm{M} \mathrm{H}_{2} \mathrm{SO}_{4}$.

\begin{tabular}{|c|c|c|c|c|c|}
\hline Component & $\begin{array}{c}\text { Solution } \\
\text { hydrolyzed by } 1 \\
\mathrm{M} \mathrm{H}_{2} \mathrm{SO}_{4}(\%) \\
\end{array}$ & $\begin{array}{c}\text { Solution } \\
\text { hydrolyzed by } \\
0.8 \mathrm{M} \mathrm{H}_{2} \mathrm{SO}_{4}(\%)\end{array}$ & $\begin{array}{c}\text { Solution } \\
\text { hydrolyzed by } \\
0.6 \mathrm{M} \mathrm{H}_{2} \mathrm{SO}_{4}\end{array}$ & $\begin{array}{c}\text { Solution } \\
\text { hydrolyzed by } \\
0.4 \mathrm{M} \mathrm{H}_{2} \mathrm{SO}_{4}\end{array}$ & $\begin{array}{c}\text { Solution } \\
\text { hydrolyzed by } \\
0.2 \mathrm{M} \mathrm{H}_{2} \mathrm{SO}_{4}\end{array}$ \\
\hline Fructose & 13.2 & 16.9 & 1.0 & 100.0 & 100.0 \\
\hline Glucose & 75.7 & 29.8 & 85.6 & - & - \\
\hline Sucrose & 11.1 & 17.6 & 13.5 & - & - \\
\hline Maltose & - & 6.2 & - & - & - \\
\hline Lactose & - & 29.6 & - & - & - \\
\hline Total & 100.0 & 100.0 & 100.0 & 100.0 & 100.0 \\
\hline
\end{tabular}

In general, the above results from HPLC indicate the presence of reducing sugars in the sample, and the amount of sugar depends on the concentration of acid used for hydrolyzing the sample. The total amount of sugar increases with increase in concentration of acid used for hydrolysis up to $0.8 \mathrm{M} \mathrm{H}_{2} \mathrm{SO}_{4}$ and decreases after while.

Similar results were also obtained by polarimetry (Table 2) indicating that maximum amount of total sugar (115.6 $\mathrm{g} / \mathrm{l})$ is obtained from the sample of $0.8 \mathrm{M}$ acid hydrolysate at $130^{\circ} \mathrm{C}$.

\section{Ethanol concentration}

The amount of ethanol in the sample was determined using refractometer which was calibrated with different percentages of standard ethanol before measurements of the samples. The data are listed in Tables 3 and 4 .

In Table 3, the highest refractive index is obtained for
$0.8 \mathrm{M}$ hydrolysate after $24 \mathrm{~h}$ fermentation. As can be seen, the refractive index increases until $24 \mathrm{~h}$ fermentation and decreases after $24 \mathrm{~h}$ for all concentrations of hydrolysate.

In the same manner, maximum refractive index is obtained for $0.8 \mathrm{M}$ hydrolysate after $24 \mathrm{~h}$ fermentation. But here the refractive index is relatively greater than the results in Table 3 . This is because the temperature in Table 4 for hydrolysis, which is $130^{\circ} \mathrm{C}$, is greater than $100^{\circ} \mathrm{C}$

\section{Ethanol concentration as a function of acid concentration and fermentation time}

The amount of ethanol in the sample was determined using refractometry. The amounts of ethanol by volume in the sample hydrolyzed with acids of different concentration for different fermentation time are given in Tables 5 and 6 . It is determined from the refractive index of the 
Table 2. Optical rotation and concentration of glucose formed after 30 min hydrolysis at 100 and $130^{\circ} \mathrm{C}$.

\begin{tabular}{|c|c|c|c|c|}
\hline $\begin{array}{l}\text { Sample } \\
\text { hydrolyzed } \\
\text { by } \mathrm{H}_{2} \mathrm{SO}_{4}(\mathrm{M})\end{array}$ & $\begin{array}{l}\alpha_{\text {obs }} /(\text { at } \\
\left.100^{\circ} \mathrm{C}\right)\end{array}$ & $\begin{array}{l}\text { Glucose conc. } / g / l \\
\left(\text { at } 100^{\circ} \mathrm{C}\right)\end{array}$ & $\begin{array}{c}a_{\text {obs }} /{ }^{\circ} \\
\left.\text { (at } 130^{\circ} \mathrm{C}\right)\end{array}$ & $\begin{array}{l}\text { Glucose conc. / } \mathrm{g} / \mathrm{l} \\
\left.\text { (at } 130^{\circ} \mathrm{C}\right)\end{array}$ \\
\hline 1.0 & 0.53 & 72.6 & 0.711 & 100.3 \\
\hline 0.8 & 0.62 & 91.1 & 0.850 & 115.6 \\
\hline 0.6 & 0.46 & 67.4 & 0.670 & 93.4 \\
\hline 0.4 & 0.41 & 56.9 & 0.493 & 70.2 \\
\hline 0.2 & 0.38 & 49.4 & 0.436 & 59.3 \\
\hline
\end{tabular}

Table 3. Refractive index of sample solution hydrolyzed at $100^{\circ} \mathrm{C}$ for $30 \mathrm{~min}$ at different concentration of sulfuric acid and at different fermentation time.

\begin{tabular}{lccccccc}
\hline \multirow{2}{*}{ No. } & \multirow{2}{*}{ Conc. of acid (M) } & \multicolumn{6}{c}{ Refractive index of the sample hydrolyzed and fermented at different time } \\
\cline { 2 - 8 } & $\mathbf{1 2} \mathbf{~}$ & $\mathbf{2 4} \mathbf{~}$ & $\mathbf{3 6} \mathbf{~}$ & $\mathbf{4 8} \mathbf{~}$ & $\mathbf{6 0} \mathbf{~}$ & $\mathbf{7 2} \mathbf{~}$ \\
\hline 1 & 1.0 & 28 & 32 & 31 & 28 & 25 & 21 \\
2 & 0.8 & 30 & 36 & 33 & 31 & 28 & 23 \\
3 & 0.6 & 27 & 31 & 30 & 26 & 23 & 19 \\
4 & 0.4 & 22 & 25 & 23 & 22 & 20 & 18 \\
5 & 0.2 & 18 & 21 & 19 & 18 & 18 & 17 \\
\hline
\end{tabular}

Table 4. Refractive index of sample solution hydrolyzed at $130^{\circ} \mathrm{C}$ for $30 \mathrm{~min}$ at different concentration of sulfuric acid and at different fermentation time.

\begin{tabular}{lccccccc}
\hline \multirow{2}{*}{ No. Conc. of acid (M) } & \multicolumn{6}{c}{ Refractive index of the sample hydrolyzed and fermented at different time } \\
\cline { 2 - 8 } & & $\mathbf{1 2} \mathbf{~}$ & $\mathbf{2 4} \mathbf{~}$ & $\mathbf{3 6} \mathbf{h}$ & $\mathbf{4 8} \mathbf{~}$ & $\mathbf{6 0} \mathbf{~}$ & $\mathbf{7 2} \mathbf{~}$ \\
\hline 1 & 1.0 & 30 & 32 & 31 & 29 & 27 & 23 \\
2 & 0.8 & 32 & 39 & 36 & 33 & 30 & 26 \\
3 & 0.6 & 29 & 33 & 31 & 28 & 25 & 20 \\
4 & 0.4 & 23 & 26 & 25 & 23 & 22 & 19 \\
5 & 0.2 & 20 & 22 & 21 & 19 & 18 & 18 \\
\hline
\end{tabular}

sample which is compared with the calibration curve (volume of ethanol versus refractive index of the standard solution).

Table 5 shows maximum volume of ethanol (13.5\%) obtained from $0.8 \mathrm{M}$ acid hydrolysate after $24 \mathrm{~h}$ fermentation. The table also shows the volume of ethanol in the sample increases with the concentration of acid used for hydrolysis. Therefore, it can be concluded that the percentage volume of ethanol increases until $24 \mathrm{~h}$ fermentation, and decrease after fermentation of $24 \mathrm{~h}$. Decrease in concentration of ethanol might be decrease in microbial mass.

As can be seen in Tables 5 and 6, the percentage volume of ethanol in the sample increases with increase in concentration of the acid used for hydrolysis of the sample (poultry manure). The tables also show that the of hydrolysis, that is, maximum amount of ethanol is obtained at $130^{\circ} \mathrm{C}$, because the temperature is optimum to break cellulosic material. The experiment shows the amount of ethanol increases until $24 \mathrm{~h}$ fermentation, but it decreases after $24 \mathrm{~h}$ fermentation because of decrease in microbial mass.

Generally, the experiment showed that the maximum percentage volume of ethanol $(14.5 \%)$ is obtained at the concentration of $0.8 \mathrm{M}$ acid hydrolyzed sample at $130^{\circ} \mathrm{C}$ and after the fermentation of $24 \mathrm{~h}$.

\section{ACKNOWLEDGEMENTS}

The authors would like to appreciate the financial support from SNNPR Mines and Energy Agency. We also thank the Head of Bonga Poultry farm, for his kind cooperation during sample collection. 
Table 5. Percentage volume of ethanol in the sample hydrolyzed at $100^{\circ} \mathrm{C}$ for 30 min at different concentration of acid and fermentation time.

\begin{tabular}{ccccccc}
\hline \multirow{2}{*}{ Conc. of acid (M) } & \multicolumn{6}{c}{ Refractive index of the sample hydrolyzed and fermented at different time } \\
\cline { 2 - 7 } & $\mathbf{1 2} \mathbf{h}$ & $\mathbf{2 4} \mathbf{~}$ & $\mathbf{3 6} \mathbf{~}$ & $\mathbf{4 8} \mathbf{~}$ & $\mathbf{6 0} \mathbf{~}$ & $\mathbf{7 2} \mathbf{~}$ \\
\hline 1.0 & 8 & 12 & 11 & 8.5 & 6 & 3 \\
0.8 & 10 & 13.5 & 12.5 & 10.5 & 8.5 & 4 \\
0.6 & 7 & 10.5 & 10 & 6 & 4 & 2 \\
0.4 & 3.5 & 5 & 4 & 3.5 & 2.5 & 1.5 \\
0.2 & 1.5 & 3 & 2 & 1.5 & 1.5 & 1 \\
\hline
\end{tabular}

Table 6. Percentage volume of ethanol in the sample hydrolyzed at $130^{\circ} \mathrm{C}$ for 30 min at different concentration of acid and fermentation time.

\begin{tabular}{ccccccc}
\hline \multirow{2}{*}{ Conc. of acid (M) } & \multicolumn{6}{c}{ Refractive index of the sample hydrolyzed and fermented at different time } \\
\cline { 2 - 7 } & $\mathbf{1 2} \mathbf{~ h}$ & $\mathbf{2 4} \mathbf{~}$ & $\mathbf{3 6} \mathbf{~}$ & $\mathbf{4 8} \mathbf{~}$ & $\mathbf{6 0} \mathbf{~}$ & $\mathbf{7 2} \mathbf{~}$ \\
\hline 1.0 & 11 & 13 & 11 & 10 & 8.5 & 4 \\
0.8 & 12 & 14.5 & 13.5 & 12.5 & 10 & 6 \\
0.6 & 9 & 12.5 & 10.5 & 8.5 & 5 & 2.5 \\
0.4 & 4 & 6 & 5 & 4 & 3.5 & 2 \\
0.2 & 2.5 & 3.5 & 3 & 2 & 1.5 & 1.5 \\
\hline
\end{tabular}

\section{REFERENCES}

Akpan UG, Alhakim AA, ljah UJ (2008). Production of ethanol fuel from organic and food wastes. J. Pract. Technol. 13(3):1-11.

Anuj KC, Ravinder R, Lakshmi MN, Rao V, Ravindra P (2007). Economic and environmental impact of bioethanol production technology. Biol. Technol. Mol. Biol. 2(2):14-32.

Attygalle A (2008). Instrumental analysis. Institute of Technology, Diaz publication, London.

Budsberg E, Rastogi M, Puettmann ME, Caputo J, Balogh S, Volk TA, Gustafson R, Johnson L (2012). Life-cycle assessment for the production of bioethanol from willow biomass crops via biochemical conversion. Forest Prod. J. 62(4):305-313.

Canettieri EV, Rocha GJ, Carvalho JA, Silva JB (2007). Optimization of acid hydrolysis from the hemicellulosic fraction of eucalyptus grandis residue using response surface methodology. Biores. Technol. 98(2):422-428.

Choge SK, Pasiecznik NM, Harvey M, Wright J, Awan SZ, Harris PJ (2007). Prosopis pods as human food, with special reference to Kenya. Forest Res. Inst. 33(3):323-335.

Dawson L, Boopaty R (2008). Cellulosic ethanol production from sugarcane bagase without enzymatic saccharification. Biores. 3(2):452-460.

Demirbas A (2005). Bioethanol from cellulosic materials: A renewable motor fuel from biomass. Energy Sources 27(5):327-337.
Gunasekaran P, Chandra KR (2007). Ethanol fermentation technology: Zymomonas mobilis. Madurai Kamary University, Madurai, India. pp. 1-22.

Licht FAO (2001). World ethanol market: Analysis and outlook. Agra Europe, London.

Licht FAO (2007). World ethanol production: To hit new record, World Ethanol and Biofuels Report.

Scott F, Quintero J, Morales M, Conejeros R, Cardona C, Aroca G (2013). Process design and sustainability in the production of bioethanol from lignocellulosic materials. Bio.Technol. 16(3):1-7.

Tanaka YL (2006). Ethanol fermentation from biomass resources: current state and prospects. Appl. Microbiol. Bio. Technol. 69(6):627642 